\title{
18
}

\section{Representation of Non-Directly Connected Impervious Area in SWMM Runoff Modeling}

\author{
Mi Chen, Sangameswaran Shyamprasad, Mitchell Heineman \\ and Christopher S. Carter
}

The overland flow runoff algorithm used in the USEPA SWMM model (Huber and Dickinson, 1988) has been a leading method for dynamic runoff simulation for over 30 years. The Runoff module in SWMM divides drainage catchments into two principal compartments, one each for impervious and pervious surfaces. Runoff discharges via a non-linear reservoir discharge equation to a drainage inlet, from where it can be routed through a collection system or downstream drainage subcatchments (Figure 18.1). SWMM44H, developed in 2002, allowed routing onto another drainage subcatchment (Huber, 2001). SWMM5, released in 2004, introduced new parameters that improve representation of typical urban runoff. The new parameters partition directly-connected impervious area (DCIA) and non-directly-connected impervious area (NDCIA) within a single catchment (Figure 18.2).

The traditional representation of an urban watershed can be quite effective in environments where impervious area dominates and runoff from pervious area is of minor importance. However, in other settings, this approach suffers from its failure to directly represent impervious areas that drain onto pervious areas, such as the cases that roofs drain onto lawns, or high impervious lands drain onto the low impact development areas or other BMP infrastructures. Explicit representation of DCIA and NDCIA better

Chen, M., S. Shyamprasad, M.C. Heineman and C.S. Carter. 2008. "Representation of Non-Directly Connected Impervious Area in SWMM Runoff Modeling." Journal of Water Management Modeling R228-18. doi: 10.14796/JWMM.R228-18.

(C) CHI 2008 www.chijournal.org ISSN: 2292-6062 (Formerly in Reliable Modeling of Urban Water Systems. ISBN: 978-0-9808853-0-9) 
represents the physical configuration of a catchment and enables more direct parameterization of physical measurements such as soil infiltration rates and imperviousness. Those parameters were traditionally first estimated and then adjusted to represent DCIA and NDCIA in the model. For example, many modelers first estimate imperviousness of a catchment and then scale that fraction downwards to represent DCIA. Some modelers scale estimated soil infiltration rates downward by the ratio of the pervious area to the sum of the pervious area and the NDCIA. When NDCIA is explicitly represented, the model's parameter for soils can instead be used to model infiltration rates that correspond with the physical soil parameters, and total imperviousness becomes a directly specified parameter, which eliminates the intermediate steps for these input data adjustments.
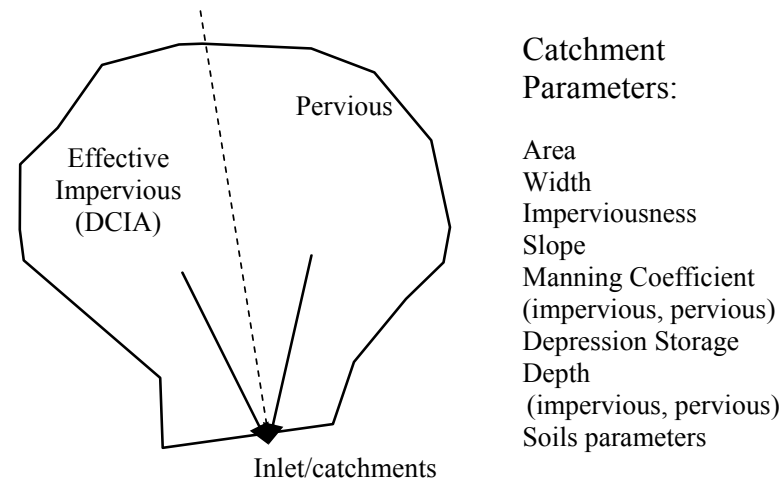

Figure 18.1 Pervious and impervious sub-areas within catchments in SWMM4.

In SWMM5, NDCIA can be controlled by the Subarea Routing and Percentage Routed parameters (Figure 18.2). Subarea Routing directs surface flow from pervious land to impervious land or vice versa. The Percentage Routed parameter controls how much flow is transferred between compartments. To use internal routing in a catchment, the Subarea Routing parameter should be changed to either PERVIOUS or IMPERVIOUS from the default value OUTLET. The Percentage Routed value then controls the transfer fraction. The PERVIOUS value directs SWMM to route run-on from impervious lands to pervious lands and the IMPERVIOUS value directs SWMM to route run-on from pervious lands to impervious lands. 
DHI's MOUSE software and Wallingford Software's InfoWorks, which are widely used for applications comparable to those modeled in SWMM, have alternative model paradigms that are more complex than the SWMM algorithms. Runoff Model B in MOUSE divides each model catchment into five compartments (versus SWMM's two), but does not route flow from one compartment to the other. The New UK Runoff Model in InfoWorks does route flow from impervious onto pervious surfaces. However, the variable percentage runoff model employed in InfoWorks possesses its own limitations (Allitt, WaPUG Spring Meeting, 2002).

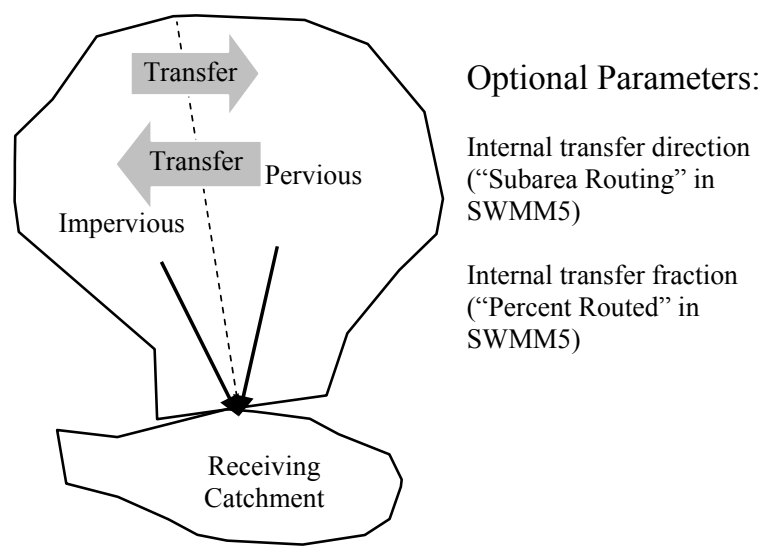

Figure 18.2 Pervious and impervious sub-areas within catchments in SWMM5.

To evaluate the influence and merits of the DCIA/NDCIA parameters on model simulations, experiments of application of DCIA/NDCIA to hypothetical catchments and to a real study area near Philadelphia, Pennsylvania were conducted.

\subsection{Experiments}

\subsubsection{Hypothetical Study Area 1}

A hypothetical study area was designed to identify the runoff changes influenced by the DCIA/NDCIA parameters. The study area contains five catchments each with an area of $2.02 \mathrm{~km}^{2}$ (499 ac) and average overland flow width of $1524 \mathrm{~m}$. The five catchments were routed to the same outlet. 
Detailed catchment parameters are listed in Table 18.1. A synthetic rainfall event with $25.4 \mathrm{~mm} / \mathrm{h}$ constant intensity over a $4 \mathrm{~h}$ duration was used. Two scenarios were created. In the first scenario, a constant $50 \%$ of runoff from the impervious land ran onto the pervious land (Percentage Routed $=50 \%$ ). The percentage of impervious land varied from $10 \%$ to $90 \%$ among the catchments. In the second scenario, the percentage of impervious land of each catchment was fixed at $50 \%$, while the Percent Routed parameter ranged from $10 \%$ to $90 \%$. The simulated total runoff and peak flow were recorded at the outlet of the study area. Evaporation and snow processes were omitted in this example and in hypothetical study area 2.

Table 18.1 Catchment parameters in the hypothetical study area 1.

\begin{tabular}{ll}
\hline Area $\left(\mathrm{km}^{2}\right)$ & 2.02 per catchment; 5 catchments \\
\hline Width $(\mathrm{m})$ & 1524 \\
Imperviousness, \% & Varying \\
Slope & 0.01 \\
Depression storage - impervious $(\mathrm{cm})$ & 0.25 \\
Depression storage - pervious $(\mathrm{cm})$ & 0.25 \\
Manning roughness - impervious & 0.1 \\
Manning roughness - pervious & 0.2 \\
Soil infiltration $(\mathrm{Green}-$ Ampt equation) & \\
Suction head $(\mathrm{cm})$ & 25.4 \\
Conductivity $(\mathrm{cm} / \mathrm{hr})$ & 25.4 \\
Initial deficit & 0.1 \\
\hline
\end{tabular}

\subsubsection{Hypothetical Study Area 2}

The same catchments were slightly reconfigured for the second scenario. The catchments had the same runoff parameters above with the exception of (case 1) $90 \%$ of impervious land with $44 \%$ of NDCIA in each catchment and (case 2) 50\% of impervious land with zero NDCIA in each catchment. This setting yielded the same $50 \%$ of DCIA in each catchment in both cases because DCIA $(\%)=$ Imperviousness $(\%) \times(1-$ NDCIA $(\%))$. The runoff simulations were conducted with saturated soil hydraulic conductivity of $254 \mathrm{~mm} / \mathrm{h}$ (extremely high) and $1.3 \mathrm{~mm} / \mathrm{h}$ (extremely low) applied in each catchment. The Green-Ampt soil infiltration equation was used. Total runoff from pervious land, and impervious land at the outlet of the study area were recorded. The current SWMM 5 only shows the total runoff at the outlet. To show the runoff from pervious and impervious separately, with the help of Robert Dickinson (2007), we modified the output format and recompiled the current SWMM 5. 


\subsection{Observations and Discussions}

\subsubsection{Hypothetical study area 1}

As expected, the first experiment showed that runoff increases with the increase in the percentage of impervious land (Figure 18.3). Figure 18.4 shows the second experiment results that the runoff out of the study area decreased with the increase in Percent Routed, which was also expected.

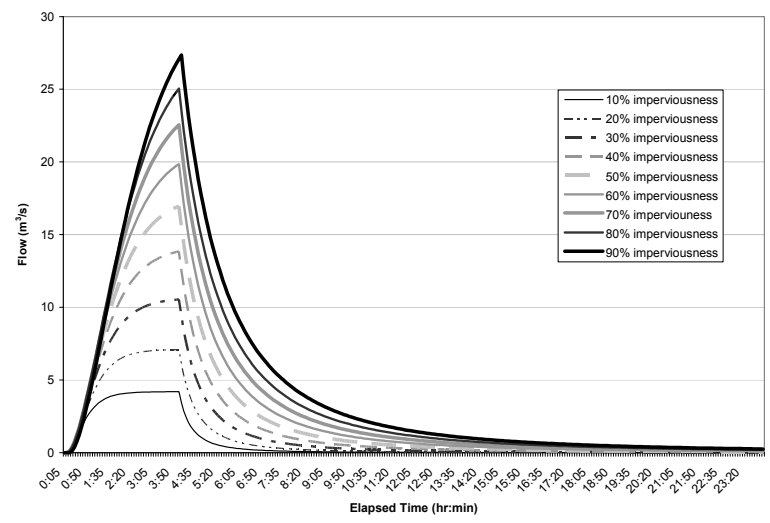

Figure18.3 Hydrographs from a study area with different imperviousness and $50 \%$ routing to pervious land

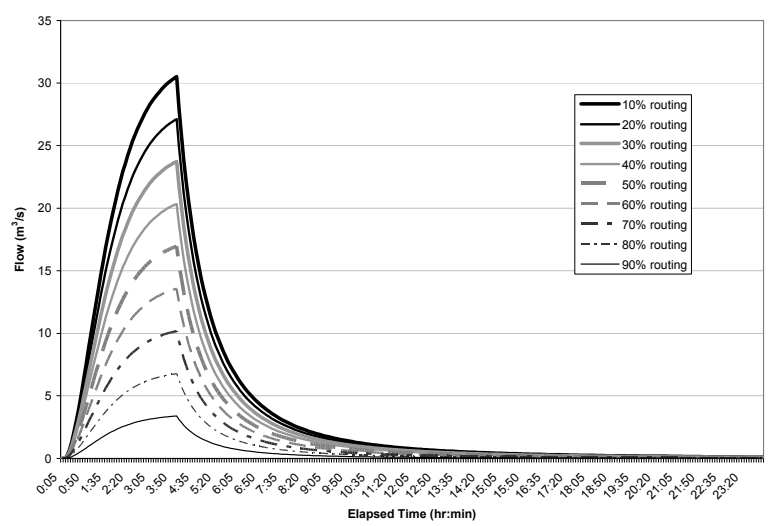

Figure 18.4 Hydrographs from a study area with $50 \%$ impervious land and different routing to pervious land 
Both experiments indicate that more runoff is generated by increasing DCIA and less runoff is produced by increasing NDCIA with more water transferred from impervious area to pervious area.

\subsubsection{Hypothetical Study 2}

Hypothetic study 2 was conducted under the same DCIA. Figure 18.5 shows the results of runoff flow from both cases with $1.3 \mathrm{~mm} / \mathrm{h}$ as the value for saturated soil hydraulic conductivity and Figure 18.6 shows the runoff flow from both cases with $254 \mathrm{~mm} / \mathrm{h}$ of soil hydraulic conductivity. Comparing these two figures, they indicate that (i) simulated runoff is influenced by consideration of the internal routing scheme although the same DCIA is used in the model, and (ii) the difference in the runoff is increased with the reduction of the soil conductivity. Inspection of runoff outflows from impervious and pervious land respectively plus the total runoff for both cases in Tables 18.2 and 18.3 reveals that (i) both type lands generated runoff when the soil conductivity was small $(1.3 \mathrm{~mm} / \mathrm{h})$ but only impervious land generated runoff when the soil conductivity was large $(254 \mathrm{~mm} / \mathrm{h})$; (ii) the total infiltration were similar with the large soil conductivity value while the total infiltration differed widely with the small soil conductivity although the same DCIA was applied in the simulations.

To find the reason for this, let us go back to the SWMM runoff module. In SWMM, runoff discharges are calculated by a non-linear reservoir equation:

$$
\mathrm{Q}=(1.49 / \mathrm{n})(\mathrm{W} / \mathrm{A})\left(\mathrm{d}-\mathrm{d}_{\mathrm{p}}\right)^{5 / 3} \mathrm{~S}^{1 / 2}
$$

where:

$$
\begin{aligned}
\mathrm{Q} & =\operatorname{runoff}\left(\mathrm{m}^{3} / \mathrm{s}\right) \\
\mathrm{n} & =\text { Manning coefficient; } \\
\mathrm{W} & =\text { the catchment width }(\mathrm{m}) ; \\
\mathrm{A} & =\text { catchment area }\left(\mathrm{m}^{2}\right) ; \\
\mathrm{d} & =\text { ponded depth }(\mathrm{m}) \\
\mathrm{d}_{\mathrm{p}} & =\text { depression storage depth }(\mathrm{m}) ; \text { and } \\
\mathrm{S} & =\text { slope. }
\end{aligned}
$$

This calculation is computed independently for pervious and impervious surfaces, as Manning coefficient normally differs between them, initial depression storage depth differs, and infiltration through pervious surfaces reduces ponded depth. 


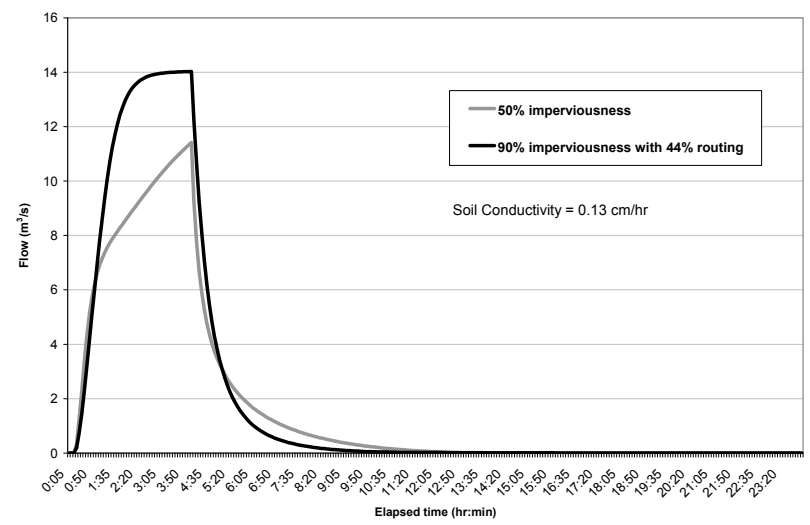

Figure 18.5 Comparison of Runoff with the same DCIA and low soil conductivity

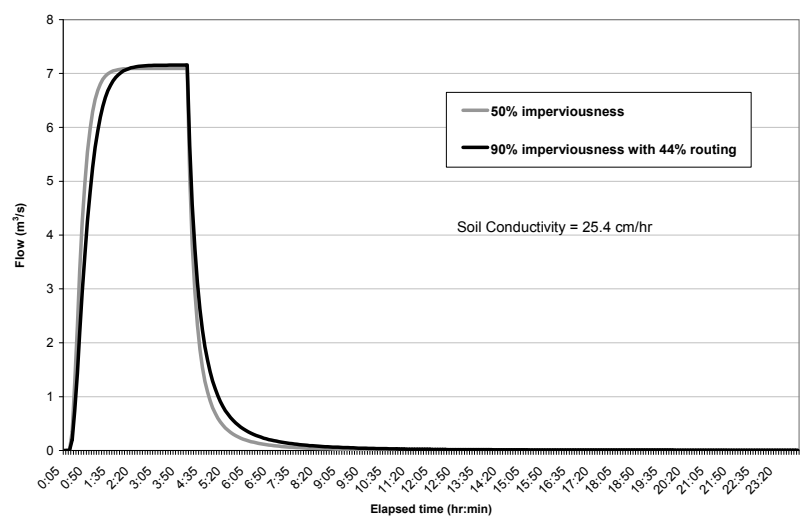

Figure 18.6 Comparison of runoff with the same DCIA and high soil conductivity

For each catchment, excluding other runoff parameters (same values used in this study), the area of the pervious land in case 1 was $10 \%$ of the total area while it is $50 \%$ in the second. Likewise, the ponded depth (d) in the first case would be higher due to the addition of the run-on from the impervious area to the smaller pervious land. So overall, with the limited soil conductivity (infiltration capability), the runoff rate should be higher in the first case, which leaves less volume available to infiltrate, or in other words, the less available soil that contacts the surface water to infiltrate. 
However, with very high soil conductivity (infiltration capability), all additional run-on from the impervious area was infiltrated into the pervious area. Therefore, the total runoff was similar from both cases due to virtually the same runoff generated from the impervious areas for both cases.

The evidence above indicates that different runoff outflows may be expected from the runoff model even when the same DCIA is used, and could be influenced by other runoff parameters such as soil infiltration capability. Thus, when calibrating a model, different DCIA may be obtained.

Table 18.2 Outflows from two scenarios with soil conductivity $=1.3 \mathrm{~mm} / \mathrm{h}$

\begin{tabular}{llllll}
\hline \multirow{2}{*}{ Scenarios } & $\begin{array}{l}\text { Total } \\
\text { Precipitation }\end{array}$ & $\begin{array}{l}\text { Total } \\
\text { Infiltration }\end{array}$ & $\begin{array}{l}\text { Impervious } \\
\text { Runoff }\end{array}$ & $\begin{array}{l}\text { Pervious } \\
\text { Runoff }\end{array}$ & Total Runoff \\
\cline { 2 - 6 } & $\mathrm{mm}$ & $\mathrm{mm}$ & $\mathrm{mm}$ & $\mathrm{mm}$ & $\mathrm{mm}$ \\
$\begin{array}{l}90 \% \\
\text { imperviousness } \\
\text { with 44\% } \\
\text { routing }\end{array}$ & 99.1 & 6.1 & 47.1 & 40.8 & 89.7 \\
\hline $\begin{array}{l}50 \% \\
\text { imperviousness }\end{array}$ & 99.1 & 22.0 & 47.6 & 27.5 & 75.1 \\
\hline
\end{tabular}

Table 18.3 Outflows from two scenarios with soil conductivity $=254 \mathrm{~mm} / \mathrm{h}$

\begin{tabular}{llllll}
\hline \multirow{2}{*}{ Scenarios } & $\begin{array}{l}\text { Total } \\
\text { Precipitation }\end{array}$ & $\begin{array}{l}\text { Total } \\
\text { Infiltration }\end{array}$ & $\begin{array}{l}\text { Impervious } \\
\text { Runoff }\end{array}$ & $\begin{array}{l}\text { Pervious } \\
\text { Runoff }\end{array}$ & Total Runoff \\
\cline { 2 - 6 } & $\mathrm{mm}$ & $\mathrm{mm}$ & $\mathrm{mm}$ & $\mathrm{mm}$ & $\mathrm{mm}$ \\
$\begin{array}{l}90 \% \\
\text { imperviousness } \\
\text { with 44\% } \\
\text { routing }\end{array}$ & 99.1 & 46.9 & 47.1 & 0.00 & 47.1 \\
\hline $\begin{array}{l}50 \% \\
\text { imperviousness }\end{array}$ & 9.91 & 49.5 & 47.6 & 0.00 & 47.6 \\
\hline
\end{tabular}

\subsection{Applications}

To test the Percentage Routed option, a study area that has a pervious area that receives contributions from an impervious region with sensitive soil characteristics was selected. 


\subsubsection{Study Area and Model Overview}

The Tacony-Creek watershed is located in southeast Pennsylvania and was selected for this analysis. A SWMM5 model developed by the Philadelphia Water Department's Office of Watersheds was used. Figure 18.7 shows the location of the study area. The watershed within the study area is shared between the City of Philadelphia and Montgomery County

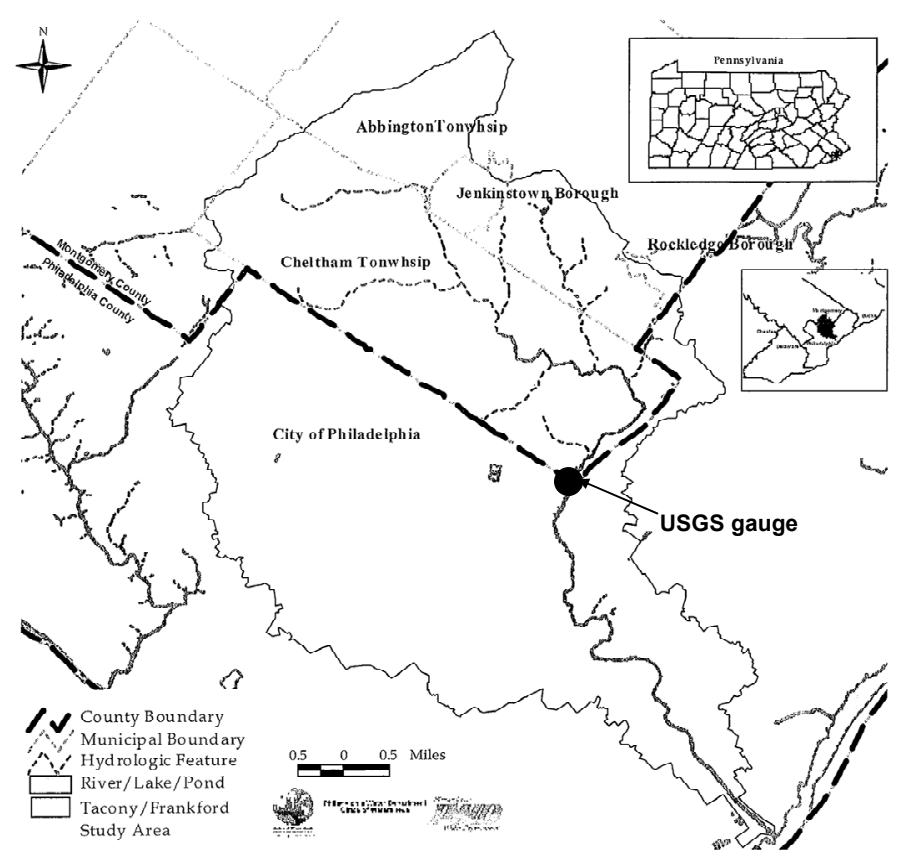

Figure 18.7 Map of Tacony Creek Watershed.

The SWMM5 model for the study area covered approximately $36 \mathrm{~km}^{2}$ $\left(14 \mathrm{mi}^{2}\right)$ and was represented by 84 catchments. The imperviousness for the area was estimated to be $35 \%$ based on GIS coverages of streets, parking lot, driveways and rooftops. The soil hydraulic conductivity ranged from 7.6 to $38.1 \mathrm{~mm} / \mathrm{h}$ for various soils ranging from silt loam to loamy sand. The hydraulics of the separate storm sewer system in this area was modeled by 
105 nodes and 105 links. The open channel was represented by a simple trapezoidal channel to reasonably represent the natural system.

The USGS streamflow gauge (01467086) at the county line near Philadelphia was used for calibrating this model. The Philadelphia Water Department maintains a network of 24 rain gauges which provided the precipitation data for this study. The period from October 2005 to February 2006 was selected as the calibration period mainly because of the availability of precipitation and observed flow data. Though this period had a total of $391.2 \mathrm{~mm}$ of precipitation, there were only three relatively large non-snowmelt storms which were used for calibration.

\subsubsection{Model Calibration}

The model was calibrated by (i) the traditional method of adjusting impervious percentage of the catchments and (ii) adjusting the Percentage routed parameters in the catchments. The main objective was to study the merits of the latter method. Figure 18.8 shows the comparison of computed flows and observed flows before calibration. Without calibration, the model estimated flows were almost twice the observed flows suggesting a significant amount of non-directly connected impervious area (NDCIA) in the system.

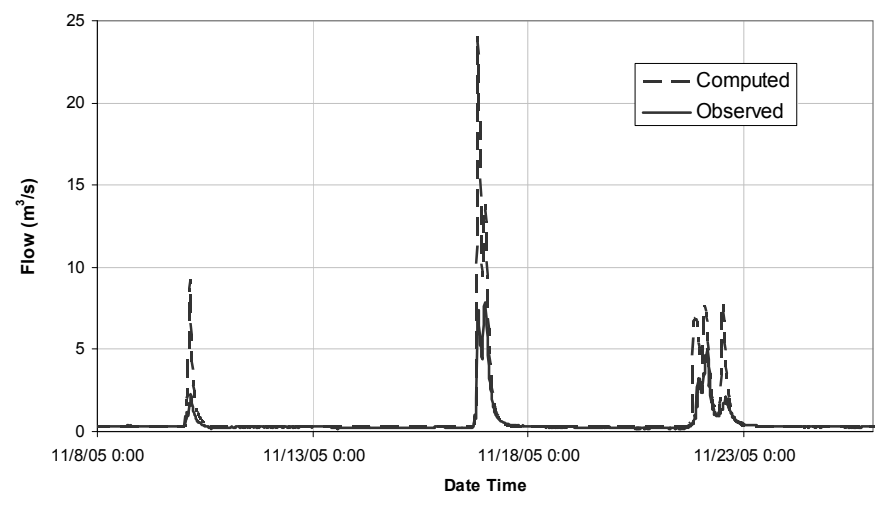

Figure 18.8 Comparison of computed flows to observed flows before calibration. 


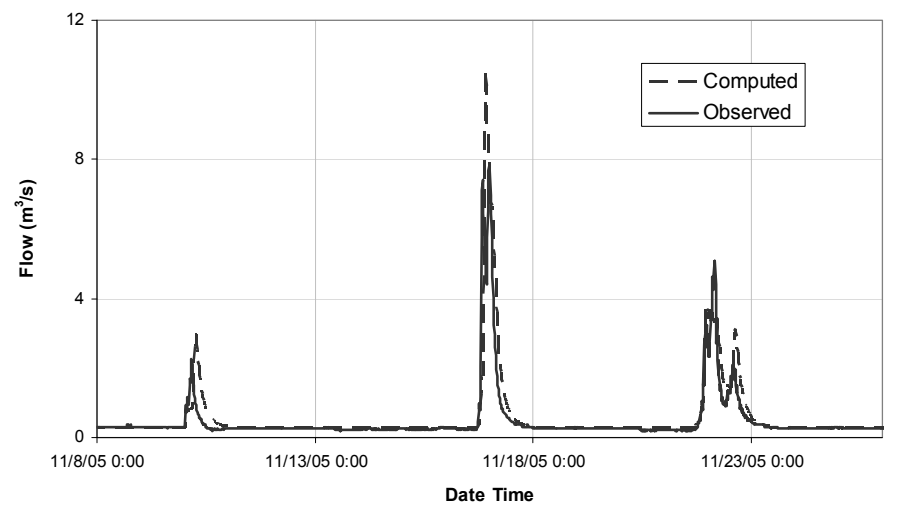

Figure 18.9 Comparison of model estimated flows to observed flows from Method 1 calibration

In the first method, the model was calibrated by adjusting the imperviousness until the computed flows matched the observed flows. Figure 18.9 shows the calibration results obtained by the reduction of the impervious percentage by $40 \%$ of the original estimated imperviousness of $35 \%$ to achieve the calibration. This resulted in an effective impervious percentage of $21 \%$.

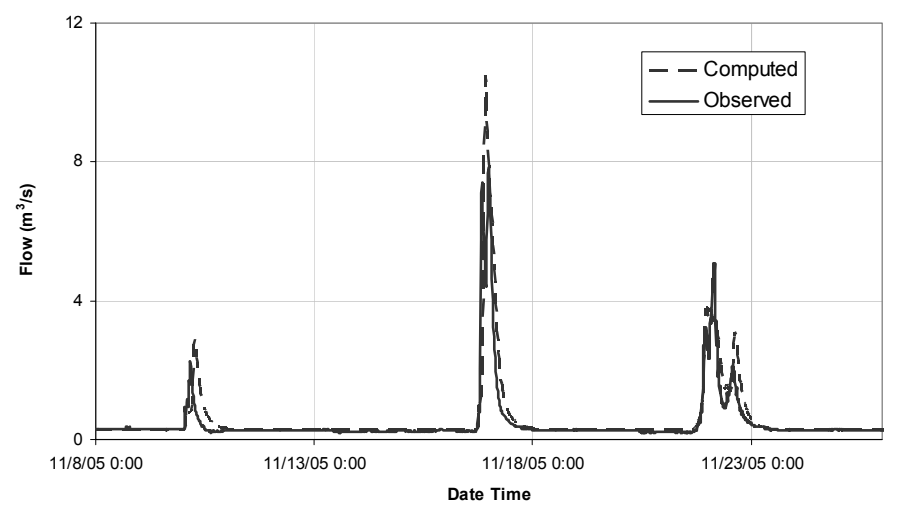

Figure18.10 Comparison of model estimated flows to observed flows from Method 2 calibration 
In the second method, the model was calibrated by adjusting the Percentage routed parameter until the modeled flows matched the observed flows. The calibrated results are shown in Figure 18.10. In this method, imperviousness was held at the originally estimated $35 \%$, and $40 \%$ of the flow was transferred from impervious to pervious portion of the catchments to achieve the calibration. This resulted in effective DCIA of $21 \%$ and effective NDCIA of $14 \%$ which is equivalent to the first method.

To verify the representation of DCIA/NDCIA to the physical observations in the studied watershed, the available GIS impervious coverage for the study area was compared to the modeling data. From this impervious coverage, total imperviousness (sum of DCIA and NDCIA) was estimated to be $35 \%$ and buildings and driveways representing NDCIA, which made up $16 \%$ of this imperviousness. Comparing our calibration suggested NDCIA of $14 \%$, we find that field data and the modeling Percentage Routed parameter agree.

This application indicated that instead of adjusting either imperviousness or soil parameters, if the Percentage Routed parameter is employed, model calibration can be achieved while still maintaining the field estimated information which allows better representation of the physical system. It should be noted that this study was limited by the availability of the rainfall data and the streamflow gauge data during the same periods. The period where both data existed did not have back to back storms which would have further explored the idea of using the Percentage Routed parameter. Since SWMM keeps track of soil saturation and drying period in both Horton and Green-Ampt infiltration methods, an enhancement of the modeling hydrology in continuous simulation by this option is expected.

\subsection{Conclusions}

New parameters Subarea Routing and Percent Routed have been introduced in the runoff module of the recent version of SWMM to calculate the internal flow routing between pervious and impervious lands in a catchment. The parameters allow user-defined percentage of run-on flows transferred from impervious area to pervious area and vice versa. As evidenced in the case studies herein, using the Percent Routed parameter/internal routing scheme in SWMM has greatly improved the parameterization to represent of typical urban runoff. However, the modelers should be aware of that the simulated runoff outflows may differ with and without using this option 
although the same Directly Connected Impervious Area (DCIA) is considered, especially under the extreme condition of soil infiltration capability.

\section{References}

Allitt, R., 2002. Rainfall, Runoff and Infiltration Re-visited. First presented to WaPUG Spring Meeting 2002 and published in March 2003.

www.wallingfordsoftware.com/articles/fullarticle.asp?ID=165

Huber, W.C. and R.E. Dickinson, Storm Water Management Model Version 4, User's Manual, EPA/600/3-88/001a (NTIS PB88-236641/AS), Environmental Protection Agency, Athens, GA, 1988, 569 pp.

Huber, W., 2001, New Options for Overland Flow Routing in SWMM. Presented at ASCE-EWRI World Water and Environmental Congress, Orlando, Florida, May 2024,2001

INFOWORKS URL: www.wallingfordsoftware.com/products/infoworks

MOUSE URL: www.dhigroup.com/Software/Urban/MOUSE.aspx

Robert E. Dickinson, 2007. Personal communication

SWMM4, http://ccee.oregonstate.edu/swmm Website accessed January 2007

SWMM5, www.epa.gov/ednnrmrl/models/swmm Website accessed January 2007 
